\title{
Kingston Caregiver Stress Scale (KCSS) Greek Validation on Dementia Caregiver Sample
}

\author{
Artemis Pitsikali ${ }^{1}$, Michael Galanakis ${ }^{2}$, Liza Varvogli ${ }^{1}$, Christina Darviri ${ }^{{ }^{*}}$ \\ ${ }^{1}$ Postgraduate Course Stress Management and Health Promotion, School of Medicine, University of Athens, \\ Athens, Greece \\ ${ }^{2}$ Panteion University of Social and Political Sciences, Athens, Greece \\ Email: ${ }^{*}$ cdarviri@yahoo.com
}

Received 27 June 2015; accepted 25 July 2015; published 30 July 2015

Copyright ( 2015 by authors and Scientific Research Publishing Inc.

This work is licensed under the Creative Commons Attribution International License (CC BY).

http://creativecommons.org/licenses/by/4.0/

(c) $\underset{\text { EY }}{\text { (i) }}$ Open Access

\begin{abstract}
In this study, we focus on the Greek validation of the Kingston Caregiver Stress Scale (KCSS) and its 3 categories: "Caregiving issues", "Family issues" and "Financial issues". Our sample consists of 100 caregivers $(N=100)$ who support a relative that suffers from a type of dementia. The participants are looking after the patients, systematically, for at least an hour per week. The questionnaires were distributed by day care centres for patients with dementia, which were located in Athens. Also, we correlated KCSS with the following questionnaires: Zarit Burden Interview (ZBI), Perceived Stress Scale (PSS), Older Americans Resources and Services (OARS), Multidimensional Functional Assessment Questionnaire (MFAQ)-Activities of Daily Living Section (ADL). The results for the reliability and the validity of the scale were satisfactory and the tool had high reliability $a=$ 0.85. We also concluded that KCSS had criterion validity as it showed a positive correlation with both ZBI and PSS, while it had a negative correlation with OARS-MFAQ-ADL.
\end{abstract}

\section{Keywords}

Validation, Kingston Caregiver Stress Scale (KCSS), Dementia Patients, Stress, Caregiver

\section{Introduction}

Stress refers to the perceived or actual threat on homeostasis of the human body (Chrousos, 1998). Homeostasis is the state that ensures the balance among physical functions through their successful synchronization (Cannon,

${ }^{*}$ Corresponding author. 
1932). Disrupted homeostasis elicits the so-called "stress response”, meaning the activation of central and peripheral neuroendocrine mechanisms that are responsible for various adaptive responses and behaviors (Chrousos, 1998). The effect of stress on physical and mental health is a matter of research, especially regarding health care professionals. Scientists have adopted 3 approaches to stress: a) the environmental approach: events in a person's life which objectively have greater adaptive requirements; b) the psychological approach: the subjective evaluations of the individual for the requirements of a stressful event; c) the biological approach: the activation of specific biological systems due to stressful events (Cohen \& Kessler, 1997). Health care professionals use questionnaires and biomarkers as measurement tools of stress.

The factors that can cause stress vary. They often represent a daily hassle or a chronic stressor (Hahn \& Smith, 1999). People who take care of a relative, who suffers from a long lasting illness such as dementia, are facing a challenge that causes a strong, continuous and stressful situation. Caregivers play an important role in supporting disadvantaged elderly people throughout dementia. Their work is not easy and is full of emotional intensity and physical exhaustion. Due to financial reasons, it is common for the relatives of the elderly to act as caregivers on a daily basis. As a result the relatives caring for such patients are characterized as "the hidden victims of the disease" (Zarit, Reever, \& Bach-Peterson, 1980).

The levels of stress can be high among caregivers of patients suffering from dementia. A survey, in which the sample consisted of elderly caregivers, showed that those who took care of a person that was suffering from dementia had higher stress levels compared to caregivers of people who suffered from other diseases such as paraplegia, arthritis and respiratory problems (Bertrand, Fredman, \& Saczynski, 2006). In another study, in the United States, women caregivers of patients with dementia, exhibited higher perceived stress in comparison to women who were occupied in different sectors (teaching, marketing, etc.) (Gallagher-Thompson et al., 2006). In another study, in the Netherlands, caregivers of persons with dementia had higher perceived stress levels compared to non caregivers, while the same results were found in many studies in the USA (De Vugt et al., 2005; Oken, Wahbeh \& Fonareva, 2011).

A relatively new psychometric tool, especially designed for the measurement of stress of caregivers is the Kingston Caregiver Stress Scale (KCSS) developed in 2005 by R.W. Hopkins and L. A. Kilik (Providence care, aging, mental health and rehabilitative care, 2015a).

The questionnaire is currently under validation of its original form and results regarding its psychometric properties are under preparation. The tool concentrates on the measurement of the change in the levels of stress of the caregiver as his or her caring situation changes (Providence care, aging, mental health and rehabilitative care, 2015b). The scale is specifically a measure of caregiver stress associated with particular activities at the present time.

The Kingston Caregiver Stress Scale (KCSS) was designed for individuals caring for someone suffering from a type of dementia. The scale is addressed to unpaid caregivers who provide care regularly in home, usually to their spouse or to another relative. The questionnaire may be handed to the caregiver for completion, or the researcher can read the items to the caregiver and ask for responses (Providence care, aging, mental health and rehabilitative care, 2015b).

The 10 questions of the scale can be divided (based on statistical analysis of the authors) into 3 categories: "Caregiving issues", "Family issues" and "Financial issues", reflecting the idea that stressors related to the caregiver everyday are multidimensional (Providence care, aging, mental health and rehabilitative care, 2015b).

The purpose of this study is the validation of the Kingston Caregiver Stress Scale (KCSS) in the Greek population. The scale was standardized in Greek after permission given by the author, R.W. Hopkins.

Finally, in order to test the validity of the KCSS, we will also correlate this scale with the questionnaires: Zarit Burden Interview (ZBI), Perceived Stress Scale (PSS), and Older Americans Resources and Services (OARS) Multidimensional Functional Assessment Questionnaire (MFAQ)-Activities of Daily Living Section. All these questionnaires serve as a criterion for the validity examination.

\section{Method}

\subsection{Sample}

For the standardization of KCSS, 100 caregivers of patients who have been diagnosed with a type of dementia completed the questionnaire (Mean Age $\mathrm{X}=56.96, \mathrm{SD}=8.40$ ). They were looking after the patients systematically for at least an hour per week. The participants in the study were not professional caregivers, but the relatives of the patients who took caregiving duties. 
As for the marital status, $72 \%$ of our sample was married, $15 \%$ single, $11 \%$ were divorced and $2 \%$ widowed. As to their profession, $10 \%$ were civil servants, $16 \%$ were employees in the private sector, $7 \%$, were freelancers and $35 \%$ were retired. $57 \%$ of the participants were living in the same house with the patient, $18 \%$ in the same building, $10 \%$ in the same neighborhood with the patient and 15\% in a different home and/or neighborhood. $15 \%$ of the caregivers were looking after the patient for one year, $21 \%$ for two years, $19 \%$ for three years and $6 \%$ for over ten years. As to the hours of care giving per week, $10 \%$ were providing care for seven hours, $12 \%$ for fourteen hours and $47 \%$ around the clock. $48 \%$ of the caregivers were taking care of their mother, $16 \%$ were taking care of their father, $31 \%$ of their spouse and $5 \%$ of another member of their family. 55\% of the sample was the sole responsible for the care, while the rest $45 \%$ was sharing the care with others. As to the type of dementia of the patient, 66\% had Alzheimer disease, $20 \%$ had vascular dementia and the remaining 14\% of our sample had another type of dementia

\subsection{Tools}

1. Kingston Caregiver Stress Scale (KCSS). (Hopkins \& Kilik, 2013). The 10 questions of the questionnaire measure the caregiver stress on a Likert scale from 1 to 5 , where $1=$ no stress (coping fine, no problems), $2=$ some stress, 3 = moderate stress, $4=$ a lot of stress and $5=$ extreme stress (feeling at "end of rope”, health at risk). Psychometric properties of the scale are under preparation from the authors.

2. Zarit Burden Interview (ZBI) (Zarit, Reever, \& Bach-Peterson, 1980; Zarit, Orr, \& Zarit, 1985; Zarit \& Zarit, 1990). Full 22-item scale. The scale consists of 22 questions and focuses on how an individual feels as to a specific caring situation. The questions are scored on a Likert scale where $0=$ never, $1=$ rarely, $2=$ sometimes, $3=$ quite frequently and $4=$ nearly always. The Greek translation was given by the MAPI Research Trust in France, after the permission given by the author of the questionnaire Steven H. Zarit

3. Perceived Stress Scale (PSS). This questionnaire consists of 14 questions that measure how persons perceive a stressful experience (Cohen, Kamarck, \& Mermelstein, 1983). Each question is rated on a Likert scale, where 0 = never, 1 = almost never, 2 = sometimes, $3=$ fairly often and $4=$ very often. In this study, we used the Greek translation of the questionnaire, after permission given by authors (Andreou et al., 2011).

4. Older Americans Resources and Services (OARS) Multidimensional Functional Assessment Questionnaire (MFAQ)-Activities of Daily Living Section. In this study we used the activities of daily living section which assesses both physical ADL and instrumental ADL of the elderly living in the community. This section consists of 14 questions and each one of them, examines whether the elderly can perform an activity a) without help, b) with some help and c) he/she is completely unable to perform it. The overall performance of the individuals is classified on a 6 point summary scale, from 6 = completely impaired ADL capacity, $5=$ severely impaired ADL capacity, 4 = moderately impaired ADL capacity, 3 = mildly impaired ADL capacity, 2 = good ADL capacity, to 1 = excellent ADL capacity. In order to use the scale, permission was given by the author Gerda G. Fillenbaum (Fillenbaum, 1978; Fillenbaum \& Smyer, 1981) and by the author of the Greek translation (Prouskas, 1999).

5. Finally, study participants filled out two more scales: caregiver's socio-demographic data and patient's socio-demographic data.

\subsection{Process}

The KCSS was translated in Greek and then was translated back in English by two experienced bilingual translators; next, the final questionnaire was discussed with a third, independent translator in order to evaluate the accuracy of the translation. Then, the scale was administered to a pilot sample of 10 people, to determine clarity and problems in completion. Finally, we made some minor changes and linguistic enhancements in order to improve the Greek version.

The questionnaires were distributed in day care centres for patients with dementia, which are located in Athens. The researchers gave instructions for the completion of the questionnaires and were present in the process for any questions from the caregivers. The purpose of the study was clarified to the participants and the questionnaires were anonymous.

The final scale consisted of two parts, the first one which concerned the caregiver himself included the following questionnaires: 1 . Socio-demographic data of the caregiver; 2. PSS; 3. KCSS; and 4. ZBI. The second part which concerned the patient and was completed by his caregiver included the following questionnaires: 1. Socio-demographic data of the patient; 2. OARS MFAQ-Activities of Daily Living Section. 
On the whole, 107 questionnaires were collected and in our statistical analysis we excluded 5 participants due to incompletion. The final sample consisted of 100 individuals, rejecting 2 caregivers who didn't answer all the questions of KCSS, in order to have more reliable results. For the statistical analysis we used the SPSS Vol.20.0.

\section{Results}

According to the statistical analysis of the KCSS scale, the variance of all the questions was satisfactory according to methodological rules and ranged from 1.159 to 2.028. There did not seem to exist any kind of polosis in any of the items. However, the participants preferred extreme answers in question 7 (Do you have concerns regarding the future care needs of your spouse/relative?), question 8 (Are you having any conflicts within your family over care decisions?), question 9 (Are you having any conflicts within your family over the amount of support you are receiving in providing care?) and question 10 (Are you having any financial difficulties associated with care giving?). In question 7 , the majority of caregivers expressed high or very high concern. On the other hand, in questions 8, 9 and 10, the majority of caregivers expressed low or moderate concern (Table 1).

\subsection{Reliability Analysis}

In order to examine the reliability of the questionnaire we used the Cronbach's Alpha (a) index. This analysis showed satisfactory reliability of the tool $(\mathrm{a}=0.85)$. In Table 2 the item analysis results are shown, according to which there is no need for item deletion, as the index does not increase in any such case.

\subsection{Validity Analysis}

Regarding the validity of the scale, we conducted a principal component analysis. The KMO index $(0.827>0.5)$

Table 1. Mean, Std. deviation and variance of the 10 questions of KCSS.

\begin{tabular}{ccccccccccc}
\hline & \multicolumn{10}{c}{ Statistics } \\
\hline \multicolumn{1}{c}{ Item No. } & KCSS 1 & KCSS 2 & KCSS 3 & KSCC4 & KSCC5 & KSCC6 & KSCC7 & KSCC8 & KSCC9 & KSCC 10 \\
\hline N Valid & 100 & 100 & 100 & 100 & 100 & 100 & 100 & 100 & 100 & 100 \\
Mean & 3.24 & 2.82 & 3.17 & 2.97 & 3.15 & 2.82 & 4.15 & 1.99 & 1.97 & 2.47 \\
Std. Deviation & 1.19 & 1.38 & 1.37 & 1.28 & 1.32 & 1.42 & 1.07 & 1.29 & 1.26 & 1.29 \\
Variance & 1.41 & 1.92 & 1.90 & 1.64 & 1.76 & 2.02 & 1.15 & 1.66 & 1.60 & 1.68 \\
\hline
\end{tabular}

Table 2. KCSS item analysis.

\begin{tabular}{|c|c|c|c|c|c|}
\hline \multicolumn{6}{|c|}{ Item-Total Statistics } \\
\hline & $\begin{array}{c}\text { Scale Mean If Item } \\
\text { Deleted }\end{array}$ & $\begin{array}{c}\text { Scale Variance If Item } \\
\text { Deleted }\end{array}$ & $\begin{array}{l}\text { Corrected Item-Total } \\
\text { Correlation }\end{array}$ & $\begin{array}{l}\text { Squared Multiple } \\
\text { Correlation }\end{array}$ & $\begin{array}{l}\text { Cronbach's Alpha If } \\
\text { Item Deleted }\end{array}$ \\
\hline KCSS1 & 25.5100 & 58.030 & 0.733 & 0.591 & 0.827 \\
\hline KCSS2 & 25.9300 & 58.046 & 0.603 & 0.431 & 0.837 \\
\hline KCSS3 & 25.5800 & 60.428 & 0.486 & 0.410 & 0.848 \\
\hline KSCC4 & 25.7800 & 56.840 & 0.737 & 0.634 & 0.825 \\
\hline KSCC5 & 25.6000 & 57.616 & 0.662 & 0.574 & 0.831 \\
\hline KSCC6 & 25.9300 & 55.116 & 0.737 & 0.576 & 0.824 \\
\hline KSCC7 & 24.6000 & 62.848 & 0.511 & 0.428 & 0.845 \\
\hline KSCC8 & 26.7600 & 64.346 & 0.325 & 0.707 & 0.860 \\
\hline KSCC9 & 26.7800 & 64.072 & 0.348 & 0.717 & 0.858 \\
\hline KSCC10 & 26.2800 & 61.335 & 0.478 & 0.300 & 0.848 \\
\hline
\end{tabular}


and the Bartlett's test of sphericity $(0.00<0.05)$ showed that our sample was sufficient in order to proceed with the factor analysis. The results of the factor analysis suggested that the questionnaire's structure could be divided into two main factors which explain $63.10 \%$ of the variance of the phenomenon. Factor 1 consists of questions 1-7 which can be named "Caregiving issues". Secondly, questions 8 and 9 constitute the second factor, which can be named "Family issues". As to question 10, although in the original KCSS questionnaire, it constitutes a different factor called "Financial issues", in our sample this particular question seems to belong to the first factor "Caregiving issues". Consequently, based on the results of the factor analysis we accept the 2 factor solution with the item loadings which are depicted in Table 3.

In order to examine the criterion validity of the questionnaire, we correlated KCSS with three other scales: PSS, ZBI and OARS-MFAQ. We expect a positive correlation with ZBI and PSS and a negative correlation with OARS-MFAQ. Based on the results on Table 4, it seems that KCSS is positively correlated to ZBI $(\mathrm{r}=+0.80$, $\mathrm{p}$ $<0.001)$ and also positively correlated to PSS $(\mathrm{r}=+0.573, \mathrm{p}<0.05)$. As to the OARS-MFAQ results there seems to be a negative correlation with KCSS whether we examine the physical activities of daily living $(\mathrm{r}=$ $-0.355, \mathrm{p}<0.05)$ or the instrumental activities of daily living $(\mathrm{r}=-0.304, \mathrm{p}<0.05)$

Finally, in order to examine the construct validity of the KCSS we estimated the intercorrelation of the KCSS subscales and the KCSS total score. The analysis shown in Table 5 proves that the two subscales have a positive correlation between them as well as with the total score of the scale. $(r=0.486-0.949, p<0.05)$.

\section{Discussion}

In conclusion the Greek Version of the KSCC seems to have satisfactory psychometric properties. The scale can be used as a valid and reliable tool for the measurement of Care Givers Stress in the Greek Population.

\begin{tabular}{ccc} 
Table 3. Factor structure of KCSS and item loadings. \\
\hline & \multicolumn{2}{c}{ Components } \\
\cline { 2 - 3 } & 0.786 & 2 \\
\hline KCSS1 & 0.698 & \\
KCSS2 & 0.646 & \\
KCSS3 & 0.839 & \\
KCSS4 & 0.800 & \\
KCSS5 & 0.775 & \\
KCSS6 & 0.714 & 0.945 \\
KCSS7 & & 0.947 \\
KCSS8 & & 0. \\
KCSS9 & 0.587 & \\
KCSS10 & & \\
\hline
\end{tabular}

Extraction Method: Principal Component Analysis. Rotation Method: Varimax with Kaiser Normalization.

Table 4. KCSS correlation to PSS. ZBI and OARS-MFAQ scores.

\begin{tabular}{|c|c|c|c|c|c|c|}
\hline \multicolumn{7}{|c|}{ Correlations } \\
\hline & & KCSS Total Stress & ZBI & PSS & $\begin{array}{l}\text { OARS-MFAQ } \\
\text { Instrumental ADL }\end{array}$ & $\begin{array}{l}\text { OARS-MFAQ } \\
\text { Physical ADL }\end{array}$ \\
\hline \multirow{3}{*}{$\begin{array}{l}\text { KCSS Total } \\
\text { Stress }\end{array}$} & Pearson Correlation & 1 & $0.802^{* *}$ & $0.573^{* *}$ & $-0.304^{* *}$ & $-0.355^{*}$ \\
\hline & Sig. (2-tailed) & & 0.000 & 0.000 & 0.002 & 0.029 \\
\hline & $\mathrm{N}$ & 100 & 100 & 100 & 100 & 100 \\
\hline
\end{tabular}

\footnotetext{
${ }^{* * *}$ Correlation is significant at the 0.01 level (2-tailed); ${ }^{*}$ Correlation is significant at the 0.05 level (2-tailed).
} 
Table 5. Construct validity of the KSCC.

\begin{tabular}{|c|c|c|c|c|}
\hline \multicolumn{5}{|c|}{ Correlations } \\
\hline & & KCSS Total Stress & KCSS Caregiving Issues & KCSS Family Issues \\
\hline \multirow{3}{*}{ KCSS Total Stress } & Pearson Correlation & 1 & $0.949^{* *}$ & $0.486^{* *}$ \\
\hline & Sig. (2-tailed) & & 0.000 & 0.000 \\
\hline & $\mathrm{N}$ & 100 & 100 & 100 \\
\hline \multirow{3}{*}{ KCSS Caregiving Issues } & Pearson Correlation & $0.949^{* *}$ & 1 & $0.219^{*}$ \\
\hline & Sig. (2-tailed) & 0.000 & & 0.029 \\
\hline & $\mathrm{N}$ & 100 & 100 & 100 \\
\hline \multirow{3}{*}{ KCSS Family Issues } & Pearson Correlation & $0.486^{* *}$ & $0.219^{*}$ & 1 \\
\hline & Sig. (2-tailed) & 0.000 & 0.029 & \\
\hline & $\mathrm{N}$ & 100 & 100 & 100 \\
\hline
\end{tabular}

${ }^{* *}$ Correlation is significant at the 0.01 level (2-tailed); ${ }^{*}$ Correlation is significant at the 0.05 level (2-tailed).

From the results, we conclude that the biggest stressor for the caregivers is their concern about the future care needs of the patient. On the other hand, participants perceive as less stressful sources, the potential conflicts that they have with their family regarding the care of the spouse/relative and the potential conflicts that they have with their family over their support in providing care. Also, the financial difficulties associated with care are considered as a low or moderate impact stressor.

In addition, in the validity analysis, question 10 which concerns the financial issues of care, in our sample seems to be part of the caregiving issues. This fact means that the caregivers face the financial difficulties of care as part of the personal issues they worry about, such as the difficulties of their everyday life and their concern about the patient.

Furthermore, according to the results of our study, when the stress of the caregivers increases, the perceived stress and the burden also increase. Furthermore, the fact that KCSS has lower positive correlation with PSS than with ZBI, can be attributed to the fact that the PSS is a general, perceived stress scale while ZBI is a more precise questionnaire, which measures the burden of caregivers/relatives of patients and is closer to the concept of our scale. In addition, the results show that when the instrumental activities of daily life and the physical activities of daily life of the patients decrease, the stress levels increase as the caregivers spend more energy and effort in order to support their relative.

Finally, the very high positive correlation of the total KCSS, with the first subscale (Caregiving issues) maybe acknowledged as an indication that participants perceive stress mainly as a result of caregiving for their beloved relatives and secondly regarding the family issues that this obligation means to them.

\section{Conclusions}

In this study, we focus on the Greek validation of the Kingston Caregiver Stress Scale (KCSS) and its 3 categories: "Caregiving issues", "Family issues" and "Financial issues". Our sample consists of caregivers who support a relative who suffers from dementia. The Greek verson of the Kingston Caregiver Stress Scale is highly reliable in our sample $\mathrm{a}=0.85$. Based on the results of this study, the scale seems to have construct and criterion validity. As a result, health care professionals have the opportunity to use the scale in order to measure the stress of caregivers. Furthermore, scientists can use KCSS, in order to design special intervention programs, reducing the strong effect of the disease on the quality of life of both patients and caregivers.

The limitations of the study were the relatively small sample and the fact that the participants were only from the city of Athens. Future studies could better be based on a nationwide and larger sample.

\section{References}

Andreou, E., Alexopoulos, E. C., Lionis, C., Varvogli, L., Gnardellis, C., Chrousos, G. P., \& Darviri, C. (2011). Perceived Stress Scale: Reliability and Validity Study in Greece. International Journal of Environmental Research and Public Health, 8, 3287-3298. http://dx.doi.org/10.3390/ijerph8083287 
Bertrand, R. M., Fredman, L., \& Saczynski, J. (2006). Are All Caregivers Created Equal? Stress in Caregivers to Adults with and without Dementia. Journal of Aging and Health, 18, 534-551. http://dx.doi.org/10.1177/0898264306289620

Cannon, W. B. (1932). The Wisdom of the Body. New York, NY: W. W. Norton \& Company, Inc.

Chrousos, G. P. (1998). Stressors, Stress, and Neuroendocrine Integration of the Adaptive Response. The 1997 Hans Selye Memorial Lecture. Annals of the New York Academy of Sciences, 851, 311-335. http://dx.doi.org/10.1111/j.1749-6632.1998.tb09006.x

Cohen, S., \& Kessler, R. C. (1997). Measuring Stress: A Guide for Health and Social Scientists. New York, NY: Oxford University Press.

Cohen, S., Kamarck, T., \& Mermelstein, R. (1983). A Global Measure of Perceived Stress. Journal of Health and Social Behavior, 24, 385-396. http://dx.doi.org/10.2307/2136404

De Vugt, M. E., Nicolson, N. A., Aalten, P., Lousberg, R., Jolle, J., \& Verhey, F. R. J. (2005). Behavioral Problems in Dementia Patients and Salivary Cortisol Patterns in Caregivers. The Journal of Neuropsychiatry Clinical Neurosciences, 17, 201-207. http://dx.doi.org/10.1176/jnp.17.2.201

Fillenbaum, G., \& Smyer, M. A. (1981). The Development, Validity, and Reliability of the Oars Multidimensional Functional Assessment Questionnaire. Journal of Gerontology, 36, 428-434. http://dx.doi.org/10.1093/geronj/36.4.428

Fillenbaum, G. (1978). Conceptualization and Development of the Multidimensional Functional Assessment Questionnaire. In: Center for the Study of Aging and Human Development (Ed.), Multidimensional Functional Assessment: The OARS methodology (pp. 16-24). Durham, NC: Duke University.

Gallagher-Thompson, D., Shurgot, G. R., Rider, K., Gray, H. L., McKibbin, C. L., Kraemer, H. C., Sephton, S. E., \& Thompson, L. W. (2006). Ethnicity, Stress, and Cortisol Function in Hispanic and Non-Hispanic White Women: A Preliminary Study of Family Dementia Caregivers and Noncaregivers. The American Journal of Geriatric Psychiatry, 14, 334-342. http://dx.doi.org/10.1097/01.JGP.0000206485.73618.87

Hahn, S. E., \& Smith, C. S. (1999). Daily Hassles and Chronic Stressors: Conceptual and Measurement Issues. Stress Medicine, 15, 89-101. http://dx.doi.org/10.1002/(SICI)1099-1700(199904)15:2<89::AID-SMI789>3.0.CO;2-O

Oken, B. S., Fonareva, I., \& Wahbeh, H. (2011). Stress-Related Cognitive Dysfunction in Dementia Caregivers. Journal of Geriatric Psychiatry and Neurology, 24, 191-198. http://dx.doi.org/10.1177/0891988711422524

Prouskas, C. (1999). Greek Translation of OARS. In S. Salek (Ed.), Compendium of Quality of Life Instruments. West Sussex: John Wiley and Sons Ltd.

Providence Care, Aging, Mental Health and Rehabilitative Care (2015a). Caregiver Stress Scale. http://nebula.wsimg.com/ac232af61ac6ad315e808f71df8e66d7?AccessKeyId=954A289F7CDF75707C10\&disposition=0 \&alloworigin $=1$

Providence Care, Aging, Mental Health and Rehabilitative Care (2015b). Administration and Interpretation Manual. http://www.providencecare.ca/clinical-tools/Kingston-Scales/Kingston\%20Scales/KCSS\%20Administration\%20and\%20I nterpretation\%20Manual.pdf

Zarit, S. H., \& Zarit, J. M. (1990). The Memory and Behavior Problems Checklist and the Burden Interview. University Park, PA: Pennsylvania State University, Gerontology Center.

Zarit, S. H., Orr, N. K., \& Zarit, J. M. (1985). The Hidden Victims of Alzheimer's Disease: Families under Stress. New York: New York University Press.

Zarit, S. H., Reever, K. E., \& Bach-Peterson, J. (1980). Relatives of the Impaired Elderly: Correlates of the Feelings of Burden. The Gerontologist, 20, 649-655. http://dx.doi.org/10.1093/geront/20.6.649 